\title{
4. PRACTICE ARCHITECTURES OF SIMULATION PEDAGOGY: FROM FIDELITY TO TRANSFORMATION
}

\author{
Nick Hopwood
}

\begin{abstract}
In this chapter, I put the theory of practice architectures to work in re-imagining simulation pedagogy in university-based professional education. I locate simulation within a broader landscape of links between higher education and the professions, before outlining key features of existing research on simulation in health professional education. This links to the empirical context underpinning the chapter: an observational study of simulation classes in an undergraduate nursing degree. I take up calls to enrich the theoretical basis for simulation pedagogy, and to shake off an attachment to the notion of 'fidelity'. Weaving practice architecture theory with Baudrillard's concepts of hyper-reality and simulacra, I analyse three moments from observed simulation classes. I show how these are constituted as productive pedagogic moments, not through a logic of mirroring stable realities of practice, but through much more fluid play between real and imagined worlds. This provides a basis from which to pinpoint the transformative potential of simulation, avoiding the traps of conservatism that accompany a view that is too closely tied to a fixed, stable reality referent. This involves a shift from simulation (re)creating practice architectures and practices based on an 'as if' logic, to simulation based on a 'what if' notion, where culturaldiscursive, material-economic, and socio-political arrangements of both real and imagined practices come together, interwoven with those of responsive, emergent pedagogy.
\end{abstract}

In this chapter, I put the theory of practice architectures to work in re-imagining simulation pedagogy in university-based professional education. I locate simulation within a broader landscape of links between higher education and the professions, before outlining key features of existing research on simulation in health professional education. This links to the empirical context underpinning the chapter: an observational study of simulation classes in an undergraduate nursing degree. I take up calls to enrich the theoretical basis for simulation pedagogy, and to shake off an attachment to the notion of 'fidelity'. Weaving practice architecture theory with Baudrillard's concepts of hyper-reality and simulacra, I analyse three moments from observed simulation classes. I show how these are constituted as productive pedagogic moments, not through a logic of mirroring stable realities of practice, but through much more fluid play between real and imagined worlds. This provides a basis from which to pinpoint the transformative potential of simulation, avoiding the traps of conservatism that accompany a view that is too closely tied to a fixed, stable reality referent. This involves a shift from simulation (re)creating practice architectures and practices based on an 'as if' logic, to simulation based on a 'what if' notion, where culturaldiscursive, material-economic, and socio-political arrangements of both real and imagined practices come together, woven together with those of responsive, emergent pedagogy.

This chapter enriches the conversation opened up in this book, exploring and developing new connections between practice architecture theory and empirical material. The theory was developed largely through close connection with studies of school-based practices. Deploying key practice architectural ideas here in the context of higher education widens the scope of application, and makes links with previous work in which the theory was used to explore health professional practices (Hopwood, Fowler, Lee, Rossiter, \& Bigsby, 2013).

Simulation immediately brings up ideas of multiple practices coming together. There are the practices being simulated (the ones 'out there' in the 'real' settings), and there are the practices of simulating - role playing, (inter)acting, materialising certain features, speaking others, relating in ways that uphold the simulation. Simulation pedagogy implies even more practices and their associated architectures: those of teaching and learning. In this chapter I do not dwell explicitly on questions of the relationship between teaching and learning, although I do pull out from the discussion of empirically document moments, instances where there are reasonable grounds for 
commentary on pedagogic effects. I also follow the 'what if' logic of the chapter's argument, and take the moments as a basis for speculative commentary. This leaves the question of the relationships between clinical practices, simulating practices, pedagogic practices, and practices of learning.

Following the broader framing of the theory of practice architectures, I view these practices in ecological relation (see Chapter 1, this volume). In so far as the project involves learning that has some positive effect on clinical practices, then they all imply each other. Simulation pedagogy brings these practices into particular relationships, occupying a niche that is not available through other pedagogic practices such as the lecture or clinical placement (discussed below). In this niche, there is interdependence between practices of clinical work, simulating, teaching, and learning. None can be taken out while leaving the niche intact. I use Baudrillard's concepts to show how this niche emerges out of such relationships: no one practice precedes the others, especially not the 'real' clinical practices 'out there'. Following non-representational logic (see below), I see simulation pedagogic practices as both a distinctive kind of practice (singular, as a space of multiplicity), and as part of an ecology of multiple (other) practices. There is no need to find a singular resolution underpinned by linear sequence.

\section{Simulation Pedagogies in the University}

\section{A bridge to professional practice}

While higher education serves diverse social, cultural and economic functions, an important role concerns the education and formation of future professionals (Abrandt Dahlgren, Dyrdal Solbrekke, Karseth, \& Nyström, 2014; Billett \& Choy, 2014; Gonzci, 2013). Billett and Choy (2014) write of the need to integrate learning experiences across university and practice settings, arguing that professional knowledge is culturally and socially situated, and materially grounded. In their view, effective professional education must help students develop conceptual perception and sensory intelligence through engaging in relevant epistemic environments. This means being and acting in settings in which particular ways of knowing are prompted, required, shared, and recognised. Thus students can be introduced to the expert or knowledge communities of their professions (Nerland \& Jensen, 2012). Nerland and Jensen (2014) argue that professional learning should be understood in relation to wider ecologies of knowledge, and that the enrolment of practitioners into profession-specific fields of knowledge is a critical condition for their successful participation in professional practices.

Making such intimate connections between university learning and the worlds of practice requires sophisticated and diverse pedagogic responses. These include placements, internships, service learning, training wards (in the case of health professional education), and simulation (see Breckwoldt, Gruber, \& Wittmann, 2014; Hopwood, Abrandt Dahlgren, \& Siwe, 2014; Hopwood, Rooney, Boud, \& Kelly, 2016; Rooney, Hopwood, Boud, \& Kelly, 2015; Lind Falk, Hammar, Hopwood, Hult, \& Abrandt Dahlgren, 2013). Simulation dates back at least to the seventeenth century in medicine, and its formal folding into university curricula spans nearly a century (see Breckwoldt et al., 2014). In recent years, however, simulation has assumed an increasingly prominent presence in higher education. I will explain reasons for this below, but will first outline and problematise some commonly held notions of what simulation-based pedagogy involves.

The simulation pedagogic practices I am referring to in this chapter occupy a particular niche within higher education. Simulations are increasingly provided as a means to further learning for working clinicians (as for pilots, military personnel, aid workers in high-risk environments). However, when undertaken in the context of a university degree, they take on a different character, and further the ends of a different and distinctive project. Of particular relevance in the higher education context is the fact that participants may have little or no experience of 'real' environments, and may find stepping into simulated roles challenging, encountering scenarios and features of them (such as time pressure, complex team work) perhaps for the first time; these might be routine and familiar to the experienced clinician. 
Simulators in (higher) education settings can take a range of forms. These include low- or no-technology role plays, affordable stand-ins for material features of practice (as when chicken fillets are used for students to practice suturing), digital models, and elaborate equipment folded into wider material reproductions, such as manikins used with recreations of hospital wards. Breckwoldt et al. (2014) write:

Simulation learning denotes learning with a safe educational environment, in which some form of reality is simulated. Learners have to learn and act within this environment... Simulation learning is a practice-based, close-to-authentic kind of learning within a learning environment which permits the design of systematic instructional efforts. (pp. 673-674)

A number of key points are surfaced here. The first is the idea that 'some form of reality is simulated'. This suggests that simulations draw from and reproduce aspects of the existing world both a common sense and problematic notion: too rigid a tie to a prior reality can undermine the pedagogic potential of simulation. There is a strong sense of simulation following an 'as if' logic here. Mentioned by Breckwoldt et al. (2014), 'close-to-authentic' learning usefully signals a preoccupation in much simulation education literature with the notion of fidelity, although the assumption that higher fidelity or more authentic equipment and experience leads to better learning has been debunked (see Dieckmann \& Krage, 2013). I would finally note the conservatism inherent in such descriptions. If the starting point is a reproductive borrowing from reality, then we risk overlooking the transformative role of simulation.

\section{Simulation in Health Professional Education}

Within health professional education more specifically, there are a number of drivers fuelling the increasing use of simulation-based pedagogy. An overarching concern is to improve patient safety and outcomes by reducing clinical errors and enhancing skills of new graduates, particularly when acting in high-pressure situations, such as critical care (Dieckman \& Krage, 2013). Related to this is the idea that simulation offers a place where mistakes can be made and particular events (such as major accidents) can be enacted without harm (Breckwoldt et al., 2014). A second issue relates to the difficulties experienced by many universities securing clinical placements for students (Arthur, Kable, \& Levett-Jones, 2011). Simulation is seen as stepping in for time in 'real' clinical environments (Issenberg, Ringsted, Østergaard, \& Dieckmann, 2011), and perhaps even having benefits over clinical placements, including increased control and standardisation over what students are exposed to.

Simulation can be used to enhance procedural skills (Hatala, Cook, Zendejas, Hamstra, \& Brydges, 2014), but is also seen as a means to accomplish certain curricular ends that are otherwise difficult. It can provide 'illustrative clarity', particularly relating to phenomena that might not be immediately or readily visible (Breckwoldt et al., 2014). For example, teaching future doctors to conduct a pelvic examination is difficult, because the work is significantly (but not totally) located within a woman's body. Hence pedagogies using plastic models, virtual representations, and professional patients have been developed (see Hopwood et al., 2014). Scenario-based simulations have emerged as a key means to integrate cognitive, motivational/affective, psychomotor and social facets of learning. They can address clinical and communication skills, and introduce other elements such as time pressure, team work, and inter-professional work (see Ahn, Rimpilainen, Abrandt Dahlgren, \& Fenwick, 2013; Nyström, Dahlberg, Hult, \& Abrandt Dahlgren, 2014).

\section{Research on simulation in health education}

There is a vast literature on simulation in health education, too large to do it full justice here. However it is possible to outline the major features of the current empirical landscape in terms of the questions and concepts that have shaped enquiry to date. The prominent questions relate to the two drivers for increased use of simulation described above. References provided below are indicative rather than exhaustive, citing review papers where possible. 
Much research on simulation in health education has focused on instrumental questions of effectiveness. Some have looked at immediate outcomes, seeking evidence that simulation helps students acquire psychomotor skills, knowledge, confidence, critical thinking, clinical judgement, and non-technical skills such as teamwork (Issenberg, McGaghie, Petrusa, Lee Gordon, \& Scalese, 2005). The 'golden egg' question is often framed as one which demonstrates that simulation approaches are effective (or more effective than others) in ensuring patient safety (Cook et al., 2013).

Linked to this are studies that seek to assess pedagogic effectiveness and inform curricular design. Arthur, Levett-Jones, and Kable (2013), Cook et al. (2013), and Dieckmann and Krage (2013) have outlined quality indicators for designing simulation learning, and success factors or barriers to effective implementation. However Berragan (2011) suggests that the theoretical basis for simulation pedagogy may be lacking or overlooked in agendas that are chiefly occupied with such operational concerns. I will return to this point later, but will first address a final central preoccupation of existing simulation pedagogy literature: fidelity.

An obvious focus relates to the degree and forms of realism of the simulator or simulation. Fidelity has numerous dimensions: physical (material), semantic (construction of meaning), and phenomenal (experience) (Dieckmann, Gaba, \& Rall, 2007). These ideas invite a practice architectural reading, which would hold that simulations are constituted not just in material set-ups, but also in the spoken, symbolic, and social dimensions of action. The accomplishment of an 'as if' world, in which a manikin becomes a patient, in which students become (however momentarily and hesitantly) nurses and doctors, is one that depends on certain material-economic, culturaldiscursive, and socio-political arrangements. A realistic simulator guarantees nothing. It must be enacted into being, touched, spoken to, responded to by people who constitute each other as practitioners in their social relations and modes of discourse.

Differing levels of fidelity are appropriate depending on the learning objectives (Arthur et al., 2013; Hatala et al., 2014). When learning is the focus, flawless recreation of the real world is less important: what matters is finding situations that help students learn, rather than ones that exactly mimic clinical counterparts (Dieckmann et al., 2007). I further undermine fidelity discourses by connecting the theory of practice architectures with Baudrillard's notions of hyperreality and simulacra. This is an important move. Norman (2014) argues that if simulation education is to 'come of age', then we must let go of fidelity and find new framing concepts. This does not mean varied dimensions of fidelity are totally ignored, but that they are approached from a view that does not stem from a correspondence or mirror-based notion of simulation.

Focusing on operational concerns and technological affordances has meant that the pedagogy of simulation has often been neglected (Berragan, 2011; Breckwoldt et al., 2014). Kaakinen and Arwood's (2009) review of simulation research in nursing for learning theory found a dominance of issues of pedagogic design and teaching, and a paucity of theoretical resources and theoretically informed research that grapple more closely with what is learned and how. Berragan (2011) points to the need for theoretical groundwork, while Schiavenato (2009) notes the problematic absence of rich theorisations, particularly in terms of building (alternative) ideological bases for simulation. Weaving the theory of practice architectures with Baudrillard can accomplish precisely this.

Re-thinking the conceptual basis of simulation pedagogy contributes to a wider project, questioning the assumptions surrounding the 'preparation' of future professionals for practice, and the role of universities in this process (Gijselaers, Dailey-Hebert, \& Niculescu, 2014; Rooney et al., 2015). The promise of practice theoretical approaches in addressing such concerns is clear (see Hopwood et al., 2014; Hopwood et al., 2016). Ahn et al. (2013) and Nyström et al. (2014) used practice theory to link multiple ways of knowing with enactments and spaces in scenario-based simulations. In such approaches, practices are held centrally in the gaze. This enables much more fluid accounts of simulation and is central to my work of disrupting notions of fidelity, and thus the entangling of the theory of practice architectures with Baudrillard's ideas. 


\section{A Different Basis for Conceptualising Simulation Pedagogy}

\section{Hyperreality and simulacra}

Baudrillard's $(1981,1983)$ concepts of hyperreality and simulacra contain the kernel of an exciting and distinctive way of understanding and re-imagining simulation pedagogies in the context of university-based professional education. Hyperreality refers to a breakdown in stable relations between a real original and a model that mirrors it. Baudrillard contended that "to simulate is to feign to have what one hasn't... simulation threatens the difference between true and false, between real and imaginary" (1983, p. 5). Rather than seeing simulations as more or less complete and faithful mirrors of reality, we can think instead of simulacra, where there is no easily fixed, stable, original. I will use the theory of practice architectures to explore how simulation pedagogies blur the lines between real and imaginary, finding value in their playful creation, rather than recreation, of presents, pasts, and futures. In this way, the logic of simulation shifts from 'as if' to 'what if'.

It may help at this point to provide a general yet concrete reference for these ideas. Theme parks often present visitors with exotic worlds: the 'wild west', the 'world of tomorrow'. The wild west does not fully or accurately reproduce the cultural-discursive, material-economic, and socialpolitical arrangements of the historical American West. There is selection, adjustment, invention. This wild west is not compromised by its infidelity. Visitors enjoy stepping into it, not because it is 'as if' the 'real', but because they are invited to step into a 'what if' scenario. This stepping is bodily and imaginary - or rather the imagination is accomplished through a whole of body act performed amid particular arrangements. The world of tomorrow even more obviously lacks a stable real referent: it was only ever imagined, it may never be. Its predictive accuracy (as if) is irrelevant. Its value comes from its possibility (what if). Baudrillard encourages us to think of more mundane and everyday features of the world in the same way. An 'as if' masquerade may be more like the themed wild west, or the imagined world of tomorrow. When they act as simulacra, they pull us into a hyper-reality where possibility opens up through fluid play between real and imagined.

Baudrillard writes: "The closer you get to perfection in simulation... the more evident it becomes... how everything escapes representation, escapes its own double and its resemblance" (1981, p. 107). There are different logics or orders of simulacra (Baudrillard, 1983). Some try to abolish difference, to pass off as real. This is not helpful in educational settings, where the aim of facilitating learning is the central project. Simulation in higher education is foremost an exercise in pedagogy, not an exercise in faking something else. One can also think of equivalence, an echo confessing the unreal while aspiring to realism. More useful are notions of what Baudrillard refers to as a third order. Here, what is simulated is no longer a counterfeit, nor an echo. Instead the relationship is reversed: the referent (the reality) proceeds from the model (the simulacrum). Third order simulacra anticipate the real. This is a powerful idea when we consider the future-oriented intentions in simulation pedagogy to change or improve practices, and increase patient safety and quality of care. If by simulating practice in the university we really are seeking to intervene in the future, then the third order will serve us much better than retrospective and reifying notions of the genuine fake or the good enough approximation.

The notion of the third order simulacrum holds that we can only ever simulate from the basis of models - it is only ever imagined versions of reality that provide the reference. It is not, for example, real clinical practice that shapes simulation laboratories and pedagogic design, but rather models of clinical practice, generalisations, patterns, certain idealised forms of care, practice scenarios. Simulation-based pedagogy proceeds through hyperrealities in which real and imagined practice architectures are in play.

Through Baudrillard (1983) we can short-circuit notions of the signifier (simulation) and signified (real practice). Reality is made volatile, rather than held still, captured, and re-presented. The real and imaginary are "confused in the same operational totality" (1983, p. 150). This chimes 
with Crookall's (2011) account of simulation, in which the relations between reality, fiction and the imagination are blurred. While this might be unsettling, it opens up significant potential to exploit the entangling of multiple practice architectures (such as those of clinical practice, those of higher education, and those of simulation) for unique and transformative pedagogic ends. If practices (real and simulated) do not have to mirror one another, but can instead take on other relational forms, then reproductive value can be replaced with something more open, emergent, and transformational. It is less about whether learners perform in pre-specified ways, and more about how they are changed through the experience, and how the experience changes what they do in future. To understand this, the theory of practice architectures is particularly helpful.

\section{Theory of practice architectures}

Questions of practices and their relationships are central to simulation pedagogy. One can immediately see how a simulation class in nursing involves multiple different practices. There are practices of clinical work and acting in scenario roles, suspending disbelief and engaging with equipment on an 'as if' basis. There are also practices of learning, of being a student in particular kinds of pedagogic relationship with the teacher and with peers. And what can we say of learning and pedagogy?

The theory of practice architectures (see Chapter 1, this volume) offers a powerful means to engage with these crucial features. It explicitly addresses questions of what practices are, how they are mediated, and how they relate to one another. The theory joins a wider movement that rejects dualisms such as mind and body, cognition and action; it recognises non-propositional knowledge, embodied and enacted through practice. This makes it particularly relevant to contexts of simulation where learning is based not on transfer of codified knowledge, but instead on bodily involvement and performance.

We may begin by recalling the view of practices as sayings, doings, and relatings (Chapter 1; Kemmis, Wilkinson, Edwards-Groves, Hardy, Grootenboer, \& Bristol, 2014). Immediately this shifts our attention away from technological affordances or fidelity of particular simulator technologies, and from pedagogic protocols. Instead, simulation is seen as constituted in utterances and understandings, modes of action, and changing social and sociomaterial relationships. Simulation cannot be reduced to any one component alone: thus the theory guards against reductive analyses that artificially sift out what are (ontologically) inseparable features. These sayings, doings, and relatings do not float in an a-teleological vacuum, but hang together in a particular project. The project reflects the intentions and aims of particular practices (Kemmis et al., 2014). The project of simulation pedagogy is one of facilitating learning. It is more about transformation (of learners, of future practices) than it is about reproduction.

The theory of practice architectures prompts us to attend to three sets of arrangements: cultural-discursive (semantic space), material-economic (physical space), and social-political (social space). This enables us to incorporate what is known to be important in terms of multiple dimensions of fidelity. But the architectural view does more than this. A traditional fidelity reading takes features from the real world 'out there', and maps their presence or absence 'in here' in the simulation classroom. Following Schatzki's (2002) site ontology, the theory of practice architectures dismantles the out there/in here dichotomy. At the site of practice, semantic, physical, and social architectures are instantiated and upheld. Simultaneously, they shape what unfolds in this particular moment in space and time. This allows for stability and change to be seen as co-present, co-occurring features of practice (Schatzki, 2013). Simulation is constituted in its own site, in which practice architectures from the clinical world, as well as others (such as practices of being an undergraduate in the university) shape what unfolds, but not deterministically. What unfolds is prefigured by these worlds, but there is always scope for difference. And these differences do not need to make some magical leap 'back in' because there is no out/in divide in the first place: a performance in the classroom is, there and then, reconstituting practices and the architectures that shape and uphold them. 
Thus a practice architectural view helps to disrupt and undermine notions of fidelity, without dismissing or losing a grip of what is known to be important. It engages with what are thought to be distinctive features of simulation-based learning, while keeping a close eye on pedagogic intent. It helps us dive into simulation concretely, by following what is said and done and the fluid relationships that unfold, but at the same time, such concrete work retains wider theoretical significance.

\section{Empirical Basis}

My analysis is based on observations of simulation classes in the final year of a Bachelor of Nursing degree. The classes were conducted as part of an elective subject focusing on critical care and deteriorating patients. Two scenario-based simulation classes were folded into the semesterlong subject. Each lasted two hours, and included either two or three scenarios (time permitting, the first was repeated with another group at the end of the class). Class size was between 20 and 30 students.

The scenarios make use of a 'high-fidelity manikin' $\left(\operatorname{SimMan}^{\mathrm{TM}}\right)$, which has a detectable pulse and is hooked up to a monitor displaying various vital signs (oxygen saturation, blood pressure, pulse etc.; see Arthur et al., 2011). These can be set remotely from a control room, but can also respond to students' actions - chest compressions are detected and reflected in the pulse reading, for example. The manikin lies on a hospital-style bed, wearing a hospital gown, and is made up with various additions such as a wig and glasses. A name band is placed on the manikin/patient's wrist, and other equipment is available, including defibrillators, surgical gloves, telephone, and so on. Students acting in clinical roles wear relevant uniforms. A technician is based in the control room, adjusting the vital signs on display by the bedside. The tutor and/or students may also be in the control room.

Each scenario is introduced through a scenario sheet that gives information about the starting condition of the patient, and a brief medical history. The sheet also states learning objectives, and includes a brief summary of the roles involved. Versions of the sheet for the tutor and sim technician also include information about changes to occur during the simulation, such as oxygen saturation, or the introduction of ectopic heart beats. The scenarios involve a number of roles for students: team leader, two registered nurses, a triage nurse, and one or more relatives of the patient. In the scenarios discussed below, the tutor plays the voice of the patient from the control room. Students who are not directly involved in the scenarios observe their peers via live video relay, in an area separated from the bedside area by a partition.

Observations and initial analysis were undertaken by a research team ${ }^{1}$. The first stages of analysis involved identifying a series of moments that we felt were of particular pedagogic interest. The team then considered what notions of pedagogy underpinned our identification and selection of these moments (i.e., why we thought they were interesting and how they related to questions of learning and teaching). The selected moments were then considered in terms of sociomaterial and practice theoretical concepts (see Hopwood et al., 2016; Rooney et al., 2015).

\section{From Fidelity to Transformation}

I will now discuss three moments that arose in these classes. I weave together the theory of practice architectures with Baudrillard's ideas of hyperreality and simulacra. In this entanglement I present a distinctive account of simulation, addressing the limitations and concerns outlined above, and offering a novel basis upon which to reimagine simulation, and through this, the role of the university in professional education.

\footnotetext{
${ }^{1}$ Observations were conducted by Nick Hopwood, Donna Rooney, David Boud, and Kate Collier. Michelle
} Kelly was also part of the research team, but was the tutor for the classes discussed in this paper. Initial analyses, including identification of key moments of pedagogic interest, were completed by all team members. 


\section{Moment 1: Architectures of clinical practice and pedagogy}

The first moment discussed in the present chapter arose while the scenario was in full swing, marked by a change in the severity of the condition of the (simulated) patient.

The tutor is 'acting' the voice of the patient from the control room. Watching what students are doing through one-way glass, she responds to their actions, asking what they are doing, answering their questions; she continues to cough and groan as if in pain, describing symptoms of difficulty breathing. After a while, the tutor glances down at her scenario sheet, and at the clock on the wall. She points to a computer monitor, and gestures to the sim technician. The technician then changes one of the vital signs. The blood pressure reading changes on the bedside monitor and the live relay screen to observing students. The acting students respond as the team leader directs them to use a nebuliser to help the patient breathe more easily.

First let us consider the action around the patient. The arrangements of clinical practice are evident here. Its cultural-discursive 'reality' is invoked through the tutor groaning as if patient. The students ask questions of and give answers to the manikin in ways that constitute and confirm the manikin as if it were a patient, and themselves as if they were clinicians. The doings are doings of clinical practice, too. The students observe and interpret the blood pressure readings, and take actions in response to them, applying a nebuliser to the 'patient'. In the social-political domain, the students relate to one another in their assigned clinical roles - as team leader, registered nurses, and so on. Their relationships with the tutor temporarily suspend the traditional student-teacher formation, and instead take on a clinician-patient form. And their relationships with the equipment produce material-economic arrangements as 'live'. The manikin itself, the manikin's voice, and the bedside monitor suggest a body that is vulnerable, experiencing pain, demanding action; the nebuliser is a device to help meet these demands. It is as if the economy of time in preserving life is real.

This is not simply clinical reality from elsewhere and the past that has been imported in or recreated: it is clinical reality produced here and now at this particular site through particular sayings, doings and relatings in response to particular cultural-discursive, social-political and material-economic arrangements. Despite the appeal of simulation because it keeps 'real' patients from harm, the practice architectures of clinical practice only come into being through practices that proceed as if harm could indeed happen to the 'patient'. Deliberate moves away from the 'real' (real pain, real harm) rely on further diving into the realm of the imaginary. This imaginary work simultaneously produces the fiction of the manikin as a patient with real demands, and needs. It is as much what if as as if. But, the sayings, doings, and relatings that ensue are no less real than those in any ward.

Other architectures are in play, too. In the control room, the tutor is both patient and tutor. Her glancing at the clock and the sheet are doings that remind us this is a class with limited time, and a pedagogic purpose. The material-economic arrangements of teaching are significant. The sheet is an instructional guide, and the clock points to the temporal economies of timetabling. At this point the project reasserts itself. While previously the tutor had focused on supporting students in stepping into the simulation, now her responsibilities to keep the scenario on time and ensure key learning objectives come into clearer view.

It is not simply that the practices and related practice architectures appear in sequence. Rather, pedagogic practices are ecologically related to other practices. The tutor and technician bring about the change in the patient, prompting actions by the students that align with learning objectives. The tutor's signal (saying) is taken up in the technician's response (doing) in a coordinated relation. And so the acting practices and clinical practices around the bedside form an ecology with the pedagogic and technical practices in the control room. The learning value of what unfolds around the bed cannot be separated from its bundling with these other architectures. The logic of simulation as mirror is inadequate here. Rather what we see is the production of learning experiences through practice architectures of multiple, interdependent practices. 


\section{Moment 2: If she had been real...}

Moment 2 emerged in a debrief discussion in the plenary area, after a scenario in which the patient, Aaron, was deteriorating, and the clinical team tried to ascertain from his girlfriend if any drugs had been taken. The material arrangements are different here - the bedside is behind the partition, the main screen is blank, and the observers have turned around, away from the screen, to face the acting students who have taken seats at the back of the plenary area.

Tutor:

So Aaron's girlfriend was by his side most of the time.

Student:

I think we did really well to try and reassure her. Actually it keeps you on track and makes you realise you need to be explaining as you go along. Probably if she was a real girlfriend and knew what they'd been doing that night, you'd probably utilise her more and maybe take her - as a Team Leader, I might have taken her aside to have a chat and say, can you talk me through the night.

Here we have moved away from the 'heat' and seductive pull of action around the bedside. Studentteacher relationships take primacy again, replacing those of clinician-patient from moments before. The social-political arrangements of teaching/learning practices reassert themselves. The tutor is facilitating the debrief, and her questions and comments prompt responses from the students. This arrangement instantiates familiar pedagogic discourse. Interestingly, some of the sayings carry forward from the scenario to this present: the student speaks as a team leader and refers to the girlfriend not her peer's real name (echoing the tutor's sayings). The cultural-discursive and socialpolitical arrangements of the scenario are not fully absented, even though its materialities are now hidden from view by the partition in the room.

This was one of many moments, in both the scenarios and the debriefs that followed them, where 'unreality' was spoken and/or acted into being. Practices ventured away from 'as if' to 'what if'. Here, it is the comment 'if she was a real girlfriend', pointing to the fact that the acting girlfriend hadn't actually been out at night with the patient. At other times, there were moments of awkwardness or giggling as the acted rather than enacted nature of the bedside practices were foregrounded. The architectures of role play, of being a student, and of equipment that is realistic but still fake and displaying mechanical or technical limitations, intrude. Just as the adage 'the map is not the territory' points to the fools' errand of the ever-more detailed map, so the 'as if' logic of simulation inevitably breaks down.

Has the simulation collapsed? Our answer depends on what we see as the project governing the practices, their associated practice architectures, and the ways these hang together. If the aim in simulation is to simulate, to help people step out of one world and into another, to suspend disbelief, to experience and become immersed - materially, bodily, affectively - in particular practices, these moments signal breakdown. The manikin as if it were a patient ceases to be. Maybe the role of girlfriend needs more detailed scripting. Perhaps the student was not a convincing actress, or struggled to improvise in ways that maintained a seamless clinical reality.

But what if this is hyperreality: not a simulation, but a simulacrum? Then there is no 'real girlfriend' referent to concern us. There is no mirror to shatter. We think instead about the productive, transformative play between real and imaginary, past, present, and future. Here, we can see how the pedagogic project remains intact, and in fact is served by the intrusion of the unreal girlfriend into the semantic space of the debrief. The student's comments enter into a 'what if' imaginary, where alternative scenarios and eventualities are considered. They go beyond the scenario that has just been enacted, and anticipate clinical practices at other times and spaces. In doing so, the student transformed the breakdown into a resource. The unrealism of the scenario provided a catalyst for sayings that extend the imagination. Indeed later, the student who played the role of the girlfriend asked, 'Could they have taken me aside and asked me?' The student reflected on practice (what has just happened), and linked this with her professional knowledge to think what might have been different. If simulation is purely about soliciting, rehearsing, or demonstrating 
embodied performances, this one has fallen short. But if it is about students coming to say, do, and relate in ways that inform their practice, sharpen their attention, and create meaningful, embodied connections between their actions and knowledge, then this moment can be counted as a success. This transformative potential arose precisely through the break from reality, venturing into imagined realms beyond the fiction of the plastic patient and his fake girlfriend.

\section{Moment 3 - Do you know what you're doing?}

The third 'moment' happened by the bedside, and was also revisited in the subsequent debrief. Notice the material set-up in the dry plastic hand, the ECG, the microphone that allows the tutor to ventriloquise the voice of the patient:

Patient [tutor]: Is the doctor coming?

Team Leader: Yes the doctor is coming to have a look at you.

Nurse 1: [Touching the manikin's dry plastic hand] He is quite sweaty and clammy.

Team Leader: Clammy.

There is a pause, and some hesitant action by the acting students.

Patient: Do you guys know what you're doing?

At this point the actors around the bedside laugh and glance at each other.

Team Leader: Yes we do. Where are we up to?

More laughter, as if his second comment undermines the first.

Team Leader: Does the ECG look normal?

Later, in the debrief:

Team Leader: I think it's very humiliating when your patient says 'guys do you know what you're doing?'

Again, laughter.

Team Leader: You have to build a trust relationship between nurses and you have to show that you know what you are doing.

Nurse 1: $\quad$ Even if you're nervous, you have to stay calm... the patient is already anxious about their own situation and if the nurses are really nervous, I think it would put more stress on the patient.

Tutor: $\quad$ Yes, so we have to be really conscious of our body language and our facial expressions, as nurses. Even if we don't feel $100 \%$ confident yet, we don't want the patient to know that. If you don't know what you're doing, you're definitely getting help from someone who does. So it's about being able to recognise your limitations. And prepare your answer when that happens to you in clinical [practice]. You'll be asked it at least once: do you know what you're doing?

There is much to be said here. The students touching the manikin's hand are enacting a disconnect between doing and saying in order to uphold the simulation: the touch is dry, but the speech reports clammy hands. The real and the imaginary collide. The uncertainty experienced by the students was perfectly real. We can see here how imagining is not just a cognitive act, existing only on an ideational plane. The imagining here is a whole-of-body act. The touch of the dry plastic, living with the rupture between doing and saying, the projection, and anticipation of what might come next ('what if' surfaces again): these are all bodily, affective, cognitive, and psychomotor in nature.

The tutor's intervention 'do you know what you're doing' was revisited later in the debrief. It linked to specific cultural-discursive and social-political dimensions, based on generalisations and expectations that are highly likely to arise in these students' early experiences after graduation. 
Invoked here is a model that suggests patients might question clinical competence. This saying was in some ways confronting, and it brought a shock and intensity into the scenario. This had an immediate effect: the team leader regrouped, and spoke out loud his thoughts, going through the clinical protocol, referring to the monitor to check the heart beat. The tutor reminded the actors and their audience of observing peers that they are not (yet) real clinicians, but in doing so pulled them further into the simulated action.

The same saying had a different effect later, in the debrief. Here it became a trigger for a discussion about the management of uncertainty in clinical practice, raising the possibility that these students might be challenged by patients in this way even when they are qualified. The tutor steered the debrief discussion to highlight emotional labour - presenting a confident, secure 'face' to patients, even when, as nurses, they might be nervous. She also took the opportunity to relay a crucial point about seeking help: another moment of transformation. This is extremely important, as students will never be fully prepared for all the eventualities they experience in practice, and thus part of 'preparedness' includes the ability to discern situations where another knowledgeable professional is needed (see Hopwood et al., 2014; Rooney et al., 2015).

This whole sequence reflects a complex interplay of the practices architectures of the various practices being enacted in the moment. The niche of simulation pedagogy emerges through fluid, interdependent relations between clinical practices, practices of simulating, and those of teaching and learning. Folding these together is the bodily work of imagining, both on 'as if' and 'what if' bases, the latter maintaining the pedagogic project when the former is ruptured. Within a project of pedagogy through hyperreality and simulacra, these relations constitute rich learning experiences. Real experiences - past (even just moments ago, as when the debrief refers back to the scenario), present (the emotions of the moment), and future (the likely challenge to career nurses' competence by patients in the early career) are brought into presence through sayings, doings, and relatings. The plastic hand is constituted as sweaty through a productive disconnect between doing and saying, drawing simultaneously on practices and practice architectures of clinical work and those of role-play, while the protocols and reference to the ECG are more synergistic. In the debrief, the architectures of pedagogy are stronger (familiar tutor-student relations resurface), but there remain traces and intrusions from the action that has just finished.

\section{Conclusion: Reflections on Where the Concepts Have Taken Us}

I have shown how multiple architectures of clinical practices and pedagogy and their fluid ecological relations within the scenario and debrief constitute a hyperreal niche, producing the simulation activities as simulacra. Through these practice architectures and the shifting between them, the students and tutor, nurses and patient, journey to and fro between the real and imaginary. The 'as if' logic is fragile, and frequently ruptured. However, the pedagogic project goes on, rescued by 'what if' work, accomplished through bodily imagination, and imaginary bodily performances. These journeys are characterised more by transformation than reproduction. What is real is as much here and now as it is a recreation of something out there. What is imagined is as much the world of clinical practice as it is the pain experienced by the plastic manikin. The real work of the simulation is the constructive and transformative enactment of imagined clinical practice. This imaginative work is held in place by a no less real, and skilfully-performed pedagogy of simulation, including careful preparation, the simulation activity, and the debrief. Despite the cold, lifeless feel of the manikin's plastic hand, its imagined pain readily stands in for the empathetically understood pain of the real patients these nurses will soon encounter in their future practice.

Students' experiences are defined, and valuable, not by virtue of their degree of realism or fidelity to an undefined 'clinical practice' said to be real, nor by unrelenting maintenance of such fidelity through unbroken suspension of disbelief. Instead, the pedagogic value of simulation lies precisely in movement across architectures, not necessarily in clean or linear sequence. It is in the intrusion of the unreal into the real, the imaginary and the fictional colliding with the world of 
consequence, pain, experienced as a confrontation with uncertainty. Simulation enables a distinctive and valuable venturing into 'what if' scenarios in a way that concretises the ethereal, embodies the cognitive, and entangles the psychomotor and the affective. 'What if,' in the moment of action around the bedside, or during the debrief, opens up possibilities for imagination that is performed bodily, 'stepping into' cultural-discursive, social-political, and material-economic arrangements simultaneously. These are not 'just' the arrangements of 'real' clinical practice. They are more than that. They are hyperreal.

If we are to achieve what Norman (2014) asserts is needed for simulation pedagogy to mature, then alternative visions are needed. The combination of practice architecture theory, with Baudrillard's notions of hyper-reality and simulacra, provides a fertile means to do this. This approach unshackles simulation from ossified notions of the real, and the conservative reproductive value that silently partners any discourse of fidelity. By embracing the unreal, and fluid play between real and imaginary, simulacra can not only draw from worlds of clinical practice and pedagogy, but can infect them. A pedagogically rich moment can unfold and be exploited for all its unreal, fake and fictional qualities. Practice can be anticipated, confronted, and, yes, changed by letting go of a tight grip on a 'real' referent and a pre-specified notion of complete, appropriate performance.

And here the theory of practice architectures bears fruit. It inherently lends itself to disrupting dominant notions of simulation pedagogy, and to enriching the theoretical basis for this field, given its occupation with practices and their relations. It provides a bridge between Baudrillard's highly general (yet generative) concepts, and concrete actions in the classroom. This approach enables the complex worlds of simulation (simulacra) to come into new clarity, and fall within our empirical grasp. It does so by providing a focus on sayings, doings, and relatings, and the practices architectures with which they are enmeshed, and offering a language to describe connections between practices. The theory of practice architectures contributes to a wider project, a critical intervention and a disruptive opening up of new ways to describe the world. The site ontological basis of this work proves valuable in the particular context of simulation pedagogy. Gone are distinctions between a stable reality 'out there' and a more or less faithful fake or reproduction 'in here'. We can, finally, let go of metaphors of the mirror and reflection, and instead dive into the entangled worlds of real and imaginary, practice and education, university and the professions. From 'as if' to 'what if', the theory of practice architectures can help to build distinctive visions for practices where pedagogy and work no longer require a bridge between them.

\section{Acknowledgements}

I would like to acknowledge that contribution of the research team members mentioned above, as well as Madeleine Abrandt Dahlgren through her role as critical friend to the project. The study was funded through a UTS Faculty of Arts \& Social Sciences Research Development Grant. I am grateful to my colleagues (editors and contributing authors to this volume) who provided feedback and immensely helpful discussion; n particular Stephen Kemmis, Christine Groves, Lil Langelotz, Kathleen Mahon, Jane Wilkinson and Susanne Francisco. I must acknowledge Kathleen for her suggestion regarding 'as if/what if' terminology - a much more articulate and elegant 'saying' than those I had grappled with previously in trying to capture my thoughts.

\section{References}

Abrandt Dahlgren, M., Dyrdal Solbrekke, T., Karseth, B., \& Nyström, S. (2014). From university to professional practice: Students as journeymen between cultures of education and work. In S. Billett, C. Harteis \& H. Gruber (Eds.), International handbook of researching professional and practice-based learning (pp. 414-484). London: Springer.

Ahn, S.-E., Rimpilainen, S., Abrandt Dahlgren, M., \& Fenwick, T. (2013, 19-21 June). Interprofessional training in technology-enhanced medical simulation: locations and 
knowings. Paper presented at the 8th International Conference on Researching Work and Learning, Stirling.

Arthur, C., Kable, A., \& Levett-Jones, T. (2011). Human patient simulation manikins and information communication technology use in Australian schools of nursing: a crosssectional survey. Clinical Simulation in Nursing, 7(6), e21-e227. doi:10.1016/j.ecns.2010.03.002

Arthur, C., Levett-Jones, T., \& Kable, A. (2013). Quality indicators for the design and implementation of simulation experiences: a Delphi study. Nurse Education Today, 33(11), 1357-1361. doi:10.1016/j.nedt.2012.07.012

Baudrillard, J. (1981). Simulacra and simulation. Ann Arbor: University of Michigan Press (trans. Sheila Glaser).

Baudrillard, J. (1983). Simulations. New York: Semiotext[e].

Berragan, L. (2011). Simulation: an effective pedagogical approach for nursing? Nurse Education Today, 31(7), 660-663. doi:10.1016/j.nedt.2011.01.019

Billett, S., \& Choy, S. (2014). Integrating professional learning experiences across university and practice settings. In S. Billett, C. Harteis \& H. Gruber (Eds.), International handbook of researching professional and practice-based learning (pp. 485-512). London: Springer.

Breckwoldt, J., Gruber, H., \& Wittmann, A. (2014). Simulation learning. In S. Billett, C. Harteis \& $\mathrm{H}$. Gruber (Eds.), International handbook of researching professional and practice-based learning (pp. 673-698). London: Springer.

Cook, D. A., Hamstra, S. J., Brydges, R., Zendejas, B., Szostek, J. H., Wang, A. T., . . Hatala, R. (2013). Comparative effectiveness of instructional design features in simulation-based education: systematic review and meta-analysis. Med Teach, 35, e867-e898. doi:10.3109/0142159X.2012.714886

Crookall, D. (2011). Philosophy and simulation. Simulation \& Gaming, 42(2), 146-150. doi:10.1177/1046878111406787

Dieckmann, P., Gaba, D. M., \& Rall, M. (2007). Deepening the theoretical foundations of patient simulation as social practice. Simulation in Healthcare, 2(3), 183-193. doi:10.1097/SIH.0b013e3180f637f5

Dieckmann, P., \& Krage, R. (2013). Simulation and psychology: Creating, recognizing and using learning opportunities. Current Opinion in Anaesthesiology, 26(6), 714-720. doi:10.1097/ACO.0000000000000018

Gijselaers, W. H., Dailey-Hebert, A., \& Niculescu, C. (2014). Shaping the new professional for the new professions. In S. Baroncelli, R. Farneti, I. Horga \& S. Vanhoonacker (Eds.), Teaching and learning the European Union: Traditional and innovative methods (pp. 9-25). London: Springer.

Gonczi, A. (2013). Competency-based approaches: Linking theory and practice in professional education with particular reference to health education. Educational Philosophy and Theory, 45(12), 1290-1306. doi:10.1080/00131857.2013.763590

Hatala, R., Cook, D., Zendejas, B., Hamstra, S., \& Brydges, R. (2014). Feedback for simulationbased procedural skills training: A meta-analysis and critical narrative synthesis. Advances in Health Sciences Education, 19(2), 251-272. doi:10.1007/s10459-013-9462-8

Hopwood, N., Fowler, C., Lee, A., Rossiter, C., \& Bigsby, M. (2013). Understanding partnership practice in child and family nursing through the concept of practice architectures. Nursing Inquiry, 20(3), 199-210. doi:10.1111/nin.12019

Hopwood, N., Abrandt Dahlgren, M., \& Siwe, K. (2014). Developing professional responsibility in medicine: a sociomaterial curriculum. In T. Fenwick \& M. Nerland (Eds.), Reconceptualising professional learning: Sociomaterial knowledges, practices, and responsibilities (pp. 171-183). London: Routledge. 
Hopwood, N., Rooney, D., Boud, D., \& Kelly, M. (2016). Simulation in higher education: a sociomaterial view. Educational Philosophy and Theory, 48(2), 165-178. doi:10.1080/00131857.2014.971403

Issenberg, S. B., McGaghie, W. C., Petrusa, E. R., Lee Gordon, D., \& Scalese, R. J. (2005). Features and uses of high-fidelity medical simulations that lead to effective learning: a BEME systematic review. Med Teach, 27(1), 10-28. doi:10.1080/01421590500046924

Issenberg, S. B., Ringsted, C., Østergaard, D., \& Dieckmann, P. (2011). Setting a research agenda for simulation-based healthcare education: A synthesis of the outcome from an Utstein style meeting. Simulation in Healthcare, 6(3), 155-167. doi:10.1097/SIH.0b013e3182207c24

Kaakinen, J., \& Arwood, E. (2009). Systematic review of nursing simulation literature for use of learning theory. International Journal of Nursing Education Scholarship, 6(1). doi:10.2202/1548-923X.1688

Kemmis, S., Wilkinson, J., Edwards-Groves, C., Hardy, I., Grootenboer, P., \& Bristol, L. (2014). Changing practices, changing education. Dordrecht: Springer.

Lind Falk, A., Hammar, M., Hopwood, N., Hult, H., \& Abrandt Dahlgren, M. (2013). One size fits all? A student ward as learning practice for interprofessional development. Journal of Interprofessional Care, Early Online (published 27 June 2013). doi:10.3109/13561820.2013.807224

Nerland, M., \& Jensen, K. (2012). Epistemic practices and object relations in professional work. Journal of Education and Work, 25(1), 101-120. doi:10.1080/13639080.2012.644909

Nerland, M., \& Jensen, K. (2014). Changing cultures of knowledge and professional learning. In S. Billett, C. Harteis \& H. Gruber (Eds.), International handbook of researching professional and practice-based learning (pp. 611-640). London: Springer.

Norman, G. (2014). Simulation comes of age. Advances in Health Sciences Education, 19(2), 143146. doi:10.1007/s10459-014-9507-7

Nyström, S., Dahlberg, J., Hult, H., \& Abrandt Dahlgren, M. (2014, 25-27 June). Crossing locations of enacting and observing simulations: ways of constructing interprofessional learning. Paper presented at the Second International ProPEL conference 'Professional Matters: Materialities and Virtualities of Professional Learning', Stirling.

Rooney, D., Hopwood, N., Boud, D., \& Kelly, M. (2015). The role of simulation in pedagogies of higher education for the health professions: through a practice-based lens. Vocations and Learning, 8(3), 269-285. doi:10.1007/s12186-015-9138-z

Schatzki, T. R. (2002). The site of the social: A philosophical account of the constitution of social life and change. University Park, PA: Pennsylvania State University Press.

Schatzki, T. R. (2013). The edge of change: on the emergence, persistence, and dissolution of practices. In E. Shove \& N. Spurling (Eds.), Sustainable practice: social theory and climate change (pp. 31-46). London: Routledge.

Schiavenato, M. (2009). Reevaluating simulation in nursing education: beyond the human patient simulator. Journal of Nursing Education, 48(7), 388-394. doi:10.3928/01484834-2009061506

\section{Affiliation}

Nick Hopwood

School of Education

University of Technology Sydney, Australia

Email correspondence: nick.hopwood@uts.edu.au 